\title{
Nutritional knowledge, nutrients intake and nutritional status of hypertensive patients in Ondo State, Nigeria
}

\author{
O.S. IJAROTIMI ${ }^{*}$ and O.O. KESHINRO ${ }^{2}$ \\ ${ }^{1}$ Department of Food Science and Technology, Federal University of Technology, Akure, Ondo State, Nigeria \\ ${ }^{2}$ Department of Human Nutrition, Faculty of Public Health, University of Ibadan, Ibadan, Oyo State, Nigeria
}

\begin{abstract}
This study aimed at assessing the anthropometry, dietary intake and micronutrient status of hypertensive patients attending specialist hospitals in Ondo State, Nigeria. A descriptive case control study was conducted among subjects attending two specialist hospitals located in Akure and Ondo towns. A total of 452 subjects (44.9\% males and 55.1\% females), was purposely selected from the study centres. A structured questionnaire was designed to collect information on demographic characteristics, socio-economic parameters, nutrition knowledge and dietary intakes of the subjects. The quantities of subjects' dietary intakes were measured using household measurements. Weight, height, systolic (SBP) and diastolic (DBP) blood pressures were measured using electronic bathroom scale, standiometer and sphygmomanometer, respectively. The subject's urine was collected; and vitamin $\mathrm{C}$, sodium, potassium, calcium, zinc and magnesium were determined using standard procedures. The results showed the following means: age $52.4 \pm 2.38$ years, weight $66.4 \pm 1.63$ $\mathrm{kg}$, height $1.64 \pm 0.01 \mathrm{~m}$, body mass index (BMI) $24.13 \pm 0.69 \mathrm{~kg} / \mathrm{m}^{2}$, SBP $124.86 \pm 2.3 \mathrm{mmHg}$ and DBP $76.22 \pm 1.86 \mathrm{mmHg}$. Blood pressure (BP) of the subjects showed that $46.9 \%$ had optimal BP, $14.2 \%$ normal BP, $11.5 \%$ high normal BP, $12.8 \%$ mild hypertension, 9.7\% moderate hypertension and 4.9\% severe hypertension. For BMI, 8.8\% were underweight, $47.1 \%$ normal, $30.3 \%$ overweight, $6.0 \%$ obesity class I, $6.0 \%$ obesity class II and $1.8 \%$ obesity class III. The proportion of hypertensive subjects that were obese was significantly $(P=0.0001)$ higher than control subjects. Three-fifth of the control subjects had good nutrition knowledge compared to one-fifth of hypertensive subjects. The estimated mean energy intake was $8.46 \mathrm{MJ}$, protein $93.1 \mathrm{~g}$, carbohydrate $314.5 \mathrm{~g}$, fat $42.9 \mathrm{~g}$, fibres $5.6 \mathrm{~g}$ and appreciable amount of vitamin C, calcium, zinc, magnesium, sodium and potassium. The subjects' urinary vitamin C concentration was $32.49 \pm 2.53 \mathrm{mg}$; calcium $0.41 \pm 0.06 \mathrm{mg}$, zinc $0.04 \pm 0.01 \mathrm{mg}$; magnesium $4.57 \pm 0.37 \mathrm{mg}$, sodium $8.33 \pm 0.37 \mathrm{mg}$ ) and potassium $7.45 \pm 0.21 \mathrm{mg}$. Statistically, there were significant differences $(P<0.05)$ between urinary vitamin $\mathrm{C}$, sodium and potassium concentration (except zinc) of hypertensive patients and the control subjects. Weak correlations were observed between the subjects' systolic $(P<0.05)$ and diastolic $(P<0.01) \mathrm{BP}$ and age, BMI and magnesium; with inverse correlations between vitamin $\mathrm{C}$, sodium and potassium. The study concluded that hypertension was significantly influenced by BMI of the subjects, which may be an indication of high intake of calories. Therefore, calorie intake should be controlled among the hypertensives.
\end{abstract}

Keywords: anthropometry, micronutrient status, hypertension, knowledge, Nigeria

\section{Introduction}

Hypertension occurs when there is excessive pressure against the blood vessel walls. The heart has to work harder in order to pump the blood through the body when it is working against this elevated pressure, and this can eventually lead to an enlarged heart, kidney and heart damage. Several epidemiological studies have reported that hypertension is common worldwide (Wolf-Maier et al., 2003) and is now regarded as a major public health problem in many countries (Murray \& Lopez, 1997). Recently, investigations have shown that over $26.4 \%$ of the world adult population had hypertension, and that by 2025 the global prevalence of hypertension would rise to 29.2\% (Cardiovascular News, 2005; JNC7, 2004). Hypertension and its complications, including stroke, heart failure, and renal failure, have been reported in both developed and developing countries (Shaper et al., 1969; Cooper \& Rotimi, 1993; WHO, 2002). The crude prevalence of hypertension in Nigeria in 1997 was $11.2 \%$ and age-adjusted prevalence was $14.5 \%$ (14.7\% for men and $14.3 \%$ for women) (Cooper et al., 1997). Hypertension and its complications constitute more than $25 \%$ of emergency medical admissions in hospitals in Nigeria and that it is the medical illness most frequently diagnosed in elderly ( $>65$ years), senior executive and army recruits among Nigerians (Okojie et al., 2000; Awoyemi et al., 2001; Ekere et al., 2005).

Studies have shown that excessive weight gain, salt intake, smoking of cigarettes and drinking of alcohol are the major predisposing factors for hypertension (Friedman et al., 1983; Kotchen et al., 1991). It is evident that diet modifications, such as reduction in energy, salt, alcohol and increase in fruits and vegetables intakes, prevent hypertension (Heyka, 1991; Hagberg et al., 2000). The benefit of micronutrients found in a diet rich in dairy products, fruit and vegetables (such as potatoes, avocados, bananas, oranges), on blood pressure has been established by

\footnotetext{
*Correspondence: O.S. Ijarotimi; E-mail:soijarotimi2000@yahoo.co.uk
} 
several studies (Heyka, 1991; Birkett, 1998; Hagberg et al., 2000). For instance, evidences have established an association between low dietary intake of calcium and high blood pressure in humans (Marcous et al., 1991; Prada et al., 1992), high sodium intakes and increase in blood pressure (Blackburn \& Prineas, 1983; Kotchen et al., 1991), low intake of potassium and increased blood pressure (Kotchen et al., 1991), magnesium deficiency and high blood pressure (Wynn \& Wynn, 1988; Leela et al., 1991), zinc supplementation (20 mg per day) and low incidence of gestational hypertension. Vitamins $\mathrm{C}$ and $\mathrm{E}$ (antioxidants) have been shown to play beneficial roles in the prevention and treatment of hypertension (May, 2000; Ettarh et al., 2002).

It is well known that maintaining normal body mass index (BMI), knowledge of nutrition and good dietary habit, such as intake of fruits and vegetables are important elements of controlling hypertension. Evidences have shown that this information is scarce in developing countries, particularly Nigeria, where hypertension has recently been recognized as a major public health problem (Okojie et al., 2000; Awoyemi et al., 2001). Therefore, this study aimed at assessing the BMI, knowledge and consumption patterns and micronutrient status of hypertensive patients attending State Specialist hospitals in Ondo State. It is envisaged that the findings would have implications for the action on the part of health and nutrition planners in the country.

\section{Materials and Methods}

\section{Study areas}

The study was conducted in Ondo State in Nigeria. Two State Specialist hospitals, located at Akure Township in Akure South Local Government Area and Ondo Township in Ondo West Local Government Area of Ondo State were included in the study. These hospitals are accessible to other villages and towns within the State; and they operated services to the patients twice in a week.

\section{Study population and sampling technique}

Four hundred and fifty-two subjects ( $\geq 20$ years old) comprised of hypertensive patients (214) and normotensive (238) were recruited from the hospitals for the study. The sampling frame consisted of all hypertensive patients attending hypertensive clinic and the normotensive (control) subjects were selected from the outpatient department of the State Specialist hospitals. This cross sectional study conducted from November
2006 to January 2007 employed a multistage sampling technique. The two State Specialist hospitals were purposively selected because of the availability of the medical facilities and also each of the hospitals has a clinical unit for hypertensive patients. The final selection of the subjects was done by simple random sampling method among the hypertensive and nonhypertensive patients.

\section{Demographic and socio-economic parameters}

Data was collected using structured questionnaires designed in English and Yoruba languages for the purpose of easier communication. The questionnaire was divided into different sections to collect information on demographic characteristics, socio-economic status, nutritional and health knowledge and dietary history and recall. The socio-economic status of the subjects was determined by considering items such as highest educational attainment, occupation and monthly income.

As regards to nutrition and health knowledge of hypertensive management, a questionnaire consisting of series of questions on the management of hypertension was administered. Each of the questions was allocated grade and the cumulative score of the respondents were used to determine their nutritional knowledge as related to hypertension (Temple, 1999). Information on dietary history of the subjects was collected and this was further buttressed by the information collected through 24-hour dietary recall method. The quantity of food intakes by the subjects were estimated using household measurements. Information concerning the recipes of food consumed by the subjects were collected, prepared and analyzed to determine their nutritional composition using a standard procedure (AOAC, 1990).

\section{Proximate/mineral compositions and gross energy of food intakes of the subjects}

The oven dried samples were subjected to proximate analysis using the method of Association of Official Analytical Chemist (AOAC, 1990). Carbohydrate content was estimated by difference. Gross energy of the dried material was determined against thermocouple grade benzoic acid using a Gallenkamp ballistic bomb calorimeter (London, UK; model CBB $-330-0104 \mathrm{~L}$ ). The sodium and potassium contents were determined by flame photometry. Other minerals (calcium, magnesium and zinc) were determined after wet digestion with a mixture of nitric, sulphuric and hydrochloric acid using Atomic Absorption Spectrophotometer (AAS Model SP9). 


\begin{abstract}
Anthropometric measurements
Anthropometric measurements (heights and weights) of the subjects were measured using the standard techniques (WHO, 1995). Training for standardization of the measurements, followed by field practice and testing was performed prior to data collection. All measurements were carried out between 9 and $12 \mathrm{hr}$. The subject wearing light clothing, was weighed to the nearest $0.1 \mathrm{~kg}$ with a Seca digital scale (Germany). Height was measured to the nearest $0.1 \mathrm{~cm}$ with a portable standiometer. The body mass index was calculated by dividing the weight in kilogramme by the square of the height in meters.
\end{abstract}

\section{Blood pressure}

Blood pressure of the subjects was measured with OMRON digital automatic blood pressure sphygmomanometer (Model HEM-712C). The blood pressure was measured on the left arm after the subject has been rested for 5 minutes in a seated position. When a blood pressure reading is taken, the higher number represents the systolic pressure (or the pressure at the peak of each heartbeat) and the lower number represents the diastolic pressure (the pressure when the heart is resting between beats). The systolic BPs (SBP) and diastolic BPs (DBP) were recorded to the nearest $2 \mathrm{mmHg}$. The values of SBP and DBP were related to the reference standard (JNC7, 2004).

\section{Collection of urine and laboratory analyses}

The first voided fasting morning urine was collected from non-institutionalized subjects (Gibbson, 1990) in brown bottle with rubber cap carefully washed with distilled water. After collection the urine samples were immediately kept in a kit containing iced blocks and later transferred into freezers prior to analysis. The urine was analyzed for magnesium, zinc, potassium, sodium and ascorbic acid (AOAC, 1990). The minerals, sodium $(\mathrm{Na})$, potassium $(\mathrm{K})$, calcium $(\mathrm{Ca})$, Zinc $(\mathrm{Zn})$, and magnesium $(\mathrm{Mg})$, were determined using atomic absorption spectrophotometer (AAS) method. For vitamin $\mathrm{C}, 10 \mathrm{ml}$. of the representative quantity of collected urine was pipetted into a conical flask and titrated immediately with the standardized solution of 2, 6 dichlorophenol indophenol to a faint pink end point which persisted for $15 \mathrm{sec}$. The ascorbic acid level in the urine was determined according to the following formula:

Ascorbic acid per $100 \mathrm{mg}=\frac{(\mathrm{V} \times \mathrm{T}) \times 100}{\mathrm{~W}}$

Where: $\mathrm{V}=\mathrm{ml}$ dye used for the titration of aliquot of diluted sample

$\mathrm{T}=$ ascorbic acid equivalent of dye solution expressed as $\mathrm{mg} / \mathrm{ml}$ of dye

$\mathrm{W}=\mathrm{g}$ of sample in aliquot titrated

\section{Data analysis}

Data was processed using the Statistical Package Software for Social Sciences (SPSS) - 12 computer software. The descriptive values were expressed in mean \pm SE and percentages of the study population. Chi square test $\left(\chi^{2}\right)$ was used to compare the blood pressures, BMI, nutritional knowledge and urinary mineral compositions of hypertensive and control subjects. Correlation analysis was used to determine the relationship between blood pressure, BMI and urinary mineral compositions.

\section{Ethical considerations}

The study protocol was approved by the ethics committee of Institute for Advanced Medical Research and Training, College of Medicine, University of Ibadan, Ibadan Nigeria.

\section{Results}

A total of 452 (males $=44.9 \%$; females $=55.1 \%$ ) subjects were involved in this study. Of the total subjects, 214 (males=90; females $=124$ ) were hypertensive. The control group included 203 males and 249 females. The mean ages of the hypertensive subjects were $68.6 \pm 3.56$ years for the males and 59.1 \pm 4.61 years for the females, while that of the control subjects were $46.4 \pm 1.49$ and $35.5 \pm 0.65$ years for the males and females, respectively. Weights of hypertensive patients were $69.2 \pm 4.89 \mathrm{~kg}$ (female) and $71.5 \pm 4.19 \mathrm{~kg}$

Table1: Mean ( \pm SEM) of demographic characteristics, anthropometric measurements and blood pressure of hypertensive patients and controlled subjects

\begin{tabular}{|c|c|c|c|c|c|}
\hline \multirow[t]{2}{*}{ Parameters } & \multicolumn{2}{|c|}{ Hypertensive Patients } & \multicolumn{2}{|c|}{ Control Subjects } & \multirow[t]{2}{*}{ Overall subjects } \\
\hline & Male & Female & Male & Female & \\
\hline Age (year) & $68.6 \pm 3.56^{C}$ & $59.1 \pm 4.61^{a b}$ & $46.4 \pm 1.49^{a}$ & $35.5 \pm 0.65^{a}$ & $52.4 \pm 2.38$ \\
\hline Weight (kg) & $71.5 \pm 4.19^{b}$ & $69.2 \pm 4.89^{b}$ & $73.4 \pm 2.60^{b}$ & $59.8 \pm 1.82^{a}$ & $66.4 \pm 1.63$ \\
\hline Height (m) & $1.69 \pm 0.01^{a}$ & $1.58 \pm 0.02^{a}$ & $1.74 \pm 0.02^{\mathrm{a}}$ & $1.62 \pm 0.0^{a}$ & $1.64 \pm 0.01$ \\
\hline BMI $\left(\mathrm{kg} / \mathrm{m}^{2}\right)$ & $24.9 \pm 1.27^{a b}$ & $27.8 \pm 1.88^{b}$ & $22.5 \pm 1.93^{a}$ & $22.8 \pm 0.66^{\mathrm{a}}$ & $24.13 \pm 0.69$ \\
\hline $\mathrm{SBP}(\mathrm{mmHg})$ & $143.0 \pm 7.89^{C}$ & $139 \pm 4.56^{\mathrm{C}}$ & $124.1 \pm 2.32^{b}$ & $112.9 \pm 1.51^{a}$ & $124.86 \pm 2.3$ \\
\hline $\mathrm{DBP}(\mathrm{mmHg})$ & $82.0 \pm 4.16^{a b}$ & $86.36 \pm 2.44^{b}$ & $70.6 \pm 1.39^{a}$ & $72.9 \pm 3.30^{a}$ & $76.22 \pm 1.86$ \\
\hline
\end{tabular}

Means with similar alphabets belong to the same homogenous subset and insignificantly different from each other $(P>0.05)$ 
(male), while control

subjects $59.8 \pm 1.82 \mathrm{~kg}$ (female) and $73.4 \pm 2.6 \mathrm{~kg}$ (male). Height of hypertensive patients $1.58 \mathrm{~m}$ (female) and $1.69 \pm 0.01 \mathrm{~m}$ (male), while for control subjects $1.62 \pm 0.01 \mathrm{~m}$ (female) and $1.74 \pm 0.02 \mathrm{~m}$ (male). BMI of hypertensive patients were $24.9 \pm 1.27 \mathrm{~kg} / \mathrm{m}^{2}$ (female) and $27.8 \pm 1.88 \mathrm{~kg} / \mathrm{m}^{2}$ (male) while control subjects were $22.5 \pm 1.93 \mathrm{~kg} / \mathrm{m}^{2}$ (female) and $27.8 \pm 0.66 \mathrm{~kg} / \mathrm{m}^{2}$ (male). The systolic blood pressure (SBP) of hypertensive patients were $143.0 \pm 7.89 \mathrm{mmHg}$ (male) and $139.0 \pm 4.56 \mathrm{mmHg}$ (female), while control subjects were $124.1 \pm 2.32 \mathrm{mmHg}$ (male) and $112.9 \pm 1.51 \mathrm{mmHg}$ (female). The mean diastolic blood pressure (DBP) for hypertensive patients was $82.0 \pm 4.16 \mathrm{mmHg}$ (male) and $86.36 \pm 2.44 \mathrm{mmHg}$ (female), while for control subjects was $70.6 \pm 1.39 \mathrm{mmHg}$ (male) and $72.9 \pm 3.30 \mathrm{mmHg}$ (female) (Table 1).

The age distribution of the subjects showed that $36 \%$ were within the age group of $20-29$ years, $18.6 \%$ were within 30-39 years and 18.1\% were between 40-49 years, while the remaining subjects $17.1 \%$ and $37.6 \%$ were within the age groups of 50-59 and 60 years and above respectively (Table 2). The occupation of the respondents showed that $7.5 \%$ had no job, $8.8 \%$ pensioners, $21.7 \%$ farmers, $27.0 \%$ civil servants, $15.5 \%$ vocational jobs and $19.5 \%$ petty trading. Educational attainment of the subjects showed that $24.8 \%$ did not have formal education background, $20.8 \%$ primary school, $25.7 \%$ secondary school, $25.2 \%$ tertiary and $3.5 \%$ higher degree. Income distribution of the sub-

Table 2: Demographic and socio-economic characteristics of the hypertensive and control subjects

\begin{tabular}{|c|c|c|c|c|}
\hline Parameters & $\begin{array}{l}\text { Hypertensive } \\
(n=214)\end{array}$ & Control $(n=238)$ & Total $=452$ & Statistic \\
\hline \multicolumn{5}{|l|}{ Age } \\
\hline $20-29$ & - & $36(15.1 \%)$ & $36(8 \%)$ & \multirow{5}{*}{$\begin{array}{l}\chi^{2}=206.4 \\
\mathrm{df}=4 \\
P=0.0001\end{array}$} \\
\hline $30-39$ & $10(4.7 \%)$ & $74(31.1 \%)$ & $84(18.6 \%)$ & \\
\hline $40-49$ & $34(15.9 \%)$ & $48(20.2 \%)$ & $82(18.1 \%)$ & \\
\hline $50-59$ & $26(12.1 \%)$ & $54(22.7 \%)$ & $80(17.7 \%)$ & \\
\hline $60+$ & $144(67.3 \%)$ & $26(10.9 \%)$ & $170(37.6 \%)$ & \\
\hline \multicolumn{5}{|l|}{ Occupation } \\
\hline None & $26(12.1 \%)$ & $8(3.4 \%)$ & $34(7.5 \%)$ & \multirow{6}{*}{$\begin{array}{l}\chi^{2}=80.33 \\
\mathrm{df}=5 \\
P=0.0001\end{array}$} \\
\hline Pensioners & $34(15.9 \%)$ & $6(2.5 \%)$ & $40(8.8 \%)$ & \\
\hline Farming & $64(29.9 \%)$ & $34(14.3 \%)$ & $98(21.7 \%)$ & \\
\hline Civil servant & $40(18.7 \%)$ & $82(34.5 \%)$ & $122(27 \%)$ & \\
\hline Vocational jobs* & $28(13.1 \%)$ & $42(17.6 \%)$ & $70(15.5 \%)$ & \\
\hline Petty trading & $22(10.3 \%)$ & $66(27.7 \%)$ & $88(19.5 \%)$ & \\
\hline \multicolumn{5}{|l|}{ Education } \\
\hline None & $78(36.4 \%)$ & $34(14.3 \%)$ & $112(24.8 \%)$ & \multirow{5}{*}{$\begin{array}{l}\chi^{2}=61.61 \\
\mathrm{df}=4 \\
P=0.0001\end{array}$} \\
\hline Primary school & $54(25.2 \%)$ & $40(16.8 \%)$ & $94(20.8 \%)$ & \\
\hline Secondary school & $46(21.5 \%)$ & $70(29.4 \%)$ & $116(25.7 \%)$ & \\
\hline Tertiary institution & $36(17 \%)$ & $78(32.8 \%)$ & $114(25.2 \%)$ & \\
\hline Higher degree & - & $16(6.7 \%)$ & $16(3.5 \%)$ & \\
\hline \multicolumn{5}{|l|}{ Monthly income } \\
\hline Uncertain & $34(15.9 \%)$ & $16(6.7 \%)$ & $50(11.1 \%)$ & \multirow{6}{*}{$\begin{array}{l}\chi^{2}=21.78 \\
\mathrm{df}=5 \\
P=0.001\end{array}$} \\
\hline US $\$ 62.5$ & $64(29.9 \%)$ & $46(19.3 \%)$ & $110(24.3 \%)$ & \\
\hline US $\$ 62.5-125$ & $52(24.3 \%)$ & $76(32 \%)$ & $128(28.3 \%)$ & \\
\hline US $\$ 125-208.33$ & $28(13.1 \%)$ & $38(15.9 \%)$ & $66(14.6 \%)$ & \\
\hline US $\$ 208.33-250$ & $22(10.3 \%)$ & $42(17.6 \%)$ & $64(14.2 \%)$ & \\
\hline US $\$ 250$ & $14(6.5 \%)$ & $20(8.4 \%)$ & $34(7.5 \%)$ & \\
\hline
\end{tabular}

*Vocational jobs= carpentry, bricklayer, hairstylist, tailoring etc; 
jects showed that $11.1 \%$ did not disclose their monthly income, $24.3 \%$ earned less than US\$62.5 per month, $28.3 \%$ earned between US\$62.5-125 per month and $14.6 \%$ earned between US\$125-208.33 per month, while the remaining subjects $14.2 \%$ earned between US\$208.33 - 250, 7.5\% earned $\geq U S \$ 250$ and $11.1 \%$ underweight subjects were $8.8 \%$, normal $47.1 \%$, overweight $30.3 \%$, obesity class $16.0 \%$, obesity class 11 6.\% and obesity class $1111.8 \%$. There was significant difference $(P=0.0001)$ between BMI of hypertensive patients and control subjects (Table 4).

The nutritional and health knowledge of $4.2 \%$ of hy-

Table 3: Classification of the subjects into different classes of blood pressure

\begin{tabular}{lllll}
\hline Classification & $\begin{array}{l}\text { Hypertensive } \\
\text { patients }\end{array}$ & $\begin{array}{l}\text { Control } \\
\text { subjects }\end{array}$ & Total subjects & Statistic \\
\hline Optimal BP & $36(16.8 \%)$ & $176(74.0 \%)$ & $212(46.9 \%)$ & \\
Normal BP & $18(8.4 \%)$ & $46(19.3 \%)$ & $64(14.2 \%)$ & $\chi^{2}=291.92$ \\
High Normal BP & $36(16.8 \%)$ & $16(6.7 \%)$ & $52(11.5 \%)$ & df $=5$ \\
Grade 1 Hypertension & $58(27.1 \%)$ & - & $58(12.8 \%)$ & $P=0.0001$ \\
Grade 2 Hypertension & $44(20.6 \%)$ & - & $44(9.7 \%)$ & \\
Grade 3 Hypertension & $22(10.3 \%)$ & - & $22(4.9 \%)$ & \\
\hline
\end{tabular}

did not disclose their monthly income.

Some $46.9 \%$ of the subjects had optimal BP, $14.2 \%$ normal BP, $11.5 \%$ high normal BP, while the remaining subjects (27.4\%) were classified as grade 1, 2, and 3 hypertension. There was a statistically significant difference between BP of the subjects with high BP than the control subjects $(P=0.0001)$ (Table 3$)$. The pertensive patients were classified as very good against $2.1 \%$ of control subjects. Twenty-eight (13.1\%) of the hypertensive patients had good knowledge against $60.9 \%(\mathrm{~N}=145)$ of control. The difference was highly significant $\left(\chi^{2}=135.12 ; \mathrm{df}=3, P=0.0001\right)$. One hundred and twelve $(52.3 \%)$ of the hypertensive patients had fair knowledge for hypertension while 83 (34.9\%) for control and $30.4 \%(\mathrm{~N}=65)$ poor for hypertension

Table 4: Nutritional status of the hypertensive and control subjects using body mass index

\begin{tabular}{|c|c|c|c|c|c|c|c|}
\hline \multirow[t]{2}{*}{ Classification } & \multicolumn{2}{|c|}{ Hypertensive } & \multicolumn{2}{|l|}{ Control } & \multicolumn{2}{|l|}{ Total } & \multirow[t]{2}{*}{ Statistic } \\
\hline & Frequency & $\%$ & Frequency & $\%$ & Frequency & $\gamma_{1}$ & \\
\hline Underweight $(\$ 18,49)$ & 19 & 8.9 & 21 & 8.8 & 40 & 8,8 & \multirow{6}{*}{$\begin{array}{l}x^{2}=55.064 \\
d=5 \\
P=0.0001\end{array}$} \\
\hline Normal $(18,5-24.9)$ & 60 & 31.8 & 145 & 60,9 & 213 & 47,1 & \\
\hline Overvieight $(25.29 .9)$ & 79 & 369 & 58 & 24,4 & 137 & 30.3 & \\
\hline Obesily class $1(30-34,9)$ & 19 & 8,9 & 8 & $3: 4$ & 27 & 6.0 & \\
\hline Obesily class II $(35-39.9)$ & 21 & 9.8 & 6 & 2.5 & 27 & 6.0 & \\
\hline Obesily class III (240) & 8 & 3.7 & 0 & 0 & 8 & 1,8 & \\
\hline
\end{tabular}

Table 5: Estimated means of energy and nutrient intakes of hypertensive patients and control subjects via 24 -hours dietary recall method

\begin{tabular}{llll}
\hline Parameters & Hypertensive & Control & Total \\
\hline Energy (Kcal.) & $1877(7.88 \mathrm{MJ})$ & $2153(9.04 \mathrm{MJ})$ & $2015(8.46 \mathrm{MJ})$ \\
Protein (g) & 86.7 & 99.4 & 93.1 \\
Carbohydrate (g) & 292.9 & 336.0 & 314.5 \\
Fat $(\mathrm{g})$ & 40.0 & 45.9 & 42.9 \\
Fibres (g) & 5.24 & 6.01 & 5.6 \\
Vitamin C (mg) & 90.75 & 77.23 & 83.9 \\
Calcium (mg) & 268.213 & 307.623 & 287.92 \\
Zinc (mg) & 12.863 & 14.753 & 13.81 \\
Magnesium (mg) & 276.788 & 317.458 & 594.25 \\
Sodium (mg) & 258.209 & 296.149 & 277.18 \\
Potassium (mg) & 294.415 & 337.675 & 316.05 \\
\hline
\end{tabular}

$\chi^{2}=3.804, \mathrm{df}=10, P=0.956$ 
against $2.1 \%(\mathrm{~N}=5)$ for control.

The mean energy intake of the subjects was 8.46MJ, protein intakes $93.1 \mathrm{~g}$, carbohydrate intake $314.5 \mathrm{~g}$, fat $42.9 \mathrm{~g}$ and fibres $5.6 \mathrm{~g}$. For the micronutrient intakes vitamin C $83.9 \mathrm{mg}$, calcium $287.92 \mathrm{mg}$, zinc $13.81 \mathrm{mg}$, magnesium $594.25 \mathrm{mg}$; sodium $277.18 \mathrm{mg}$ and potassium $316.05 \mathrm{mg}$. There was no significant difference $(P=0.956)$ between the nutrient intakes of the hypertensive subjects and non-hypertensive (male hypertensive patients), sodium $3.99 \pm 0.24 \mathrm{mg}$ (male patient subjects) and $10.34 \pm 0.15 \mathrm{mg}$ (female controlled subjects) and potassium 5.19 $\pm 0.38 \mathrm{mg}$ (male patient subjects) and $8.45 \pm 0.16 \mathrm{mg}$ (female control). There were significant differences $(P<0.05)$ between the vitamin $C$, sodium and potassium levels of hypertensive patients and the controlled subjects (Table 6).

It was observed that there were correlations

Table: 6 Mean ( \pm SEM) of selected micronutrients status of hypertensive patients and control subjects via urinary analysis

\begin{tabular}{llllll}
\hline \multirow{2}{*}{ Parameters } & \multicolumn{2}{l}{ Hypertensive Patients } & \multicolumn{2}{l}{ Control Subject } & \multicolumn{2}{l}{ Overall } \\
Male & Male & Female & subjects \\
\hline Vitamin C (mg) & $14.96 \pm 1.92^{\mathrm{a}}$ & $18.77 \pm 3.02^{\mathrm{a}}$ & $37.63 \pm 4.28^{\mathrm{b}}$ & $40.87 \pm 4.18^{\mathrm{b}}$ & $32.49 \pm 2.53$ \\
Calcium (mg) & $0.41 \pm 0.29^{\mathrm{ab}}$ & $0.11 \pm 0.02^{\mathrm{a}}$ & $0.56 \pm 0.14^{\mathrm{b}}$ & $0.47 \pm 0.08^{\mathrm{ab}}$ & $0.41 \pm 0.06$ \\
Zinc (mg) & $0.03 \pm 0.0^{\mathrm{a}}$ & $0.05 \pm 0.01^{\mathrm{a}}$ & $0.02 \pm 0.02^{\mathrm{a}}$ & $0.05 \pm 0.02^{\mathrm{a}}$ & $0.04 \pm 0.01$ \\
Magnesium (mg) & $6.91 \pm 0.48^{\mathrm{C}}$ & $5.83 \pm 0.68^{\mathrm{bc}}$ & $4.64 \pm 0.88^{\mathrm{ab}}$ & $3.33 \pm 0.54^{\mathrm{a}}$ & $4.57 \pm 0.37$ \\
Sodium (mg) & $3.99 \pm 0.24^{\mathrm{a}}$ & $4.28 \pm 0.34^{\mathrm{a}}$ & $10.23 \pm 0.24^{\mathrm{b}}$ & $10.34 \pm 0.15^{\mathrm{b}}$ & $8.33 \pm 0.37$ \\
Potassium (mg) & $5.19 \pm 0.38^{\mathrm{a}}$ & $5.45 \pm 0.36^{\mathrm{a}}$ & $8.48 \pm 0.16^{\mathrm{b}}$ & $8.45 \pm 0.16^{\mathrm{b}}$ & $7.45 \pm 0.21$ \\
Na/K ratio (mg) & $0.808 \pm 0.09^{\mathrm{a}}$ & $0.806 \pm 0.22^{\mathrm{a}}$ & $1.21 \pm 0.02^{\mathrm{b}}$ & $1.24 \pm 0.03^{\mathrm{b}}$ & $1.09 \pm 0.03$ \\
\hline
\end{tabular}

Means with similar alphabets belong to the same homogenous subset and insignificantly different from each other $(P>0.05)$

Table 7: Correlation between demographic characteristics, anthropometric measurements, blood pressures and selected urinary micronutrients $(\mathrm{P}<0.05)$

\begin{tabular}{|c|c|c|c|c|c|c|c|c|c|c|c|c|}
\hline & Sex & Age & $\mathrm{BMI}$ & SBP & DBP & Vit C & $\mathrm{Mg}$ & $\mathrm{Ca}$ & $\mathrm{Zn}$ & $\mathrm{Na}$ & $\mathrm{K}$ & NA/K \\
\hline Sex & 1.00 & & & & & & & & & & & \\
\hline Age & -0.82 & 1.00 & & & & & & & & & & \\
\hline BMI & -0.26 & $0.27^{a}$ & 1.00 & & & & & & & & & \\
\hline SBP & -0.48 & $0.52^{b}$ & $0.42^{b}$ & 1.00 & & & & & & & & \\
\hline DBP & -0.33 & $0.25^{\mathrm{a}}$ & $0.33^{b}$ & $0.50^{b}$ & 1.00 & & & & & & & \\
\hline Vit C & 0.44 & $-0.45^{b}$ & -0.13 & $-0.40^{b}$ & $-0.27^{a}$ & 1.00 & & & & & & \\
\hline $\mathrm{Mg}$ & -0.31 & $0.43^{b}$ & 0.04 & $0.31^{b}$ & 0.12 & -0.14 & 1.00 & & & & & \\
\hline $\mathrm{Ca}$ & 0.17 & $-0.33^{b}$ & -0.05 & -0.04 & 0.10 & 0.07 & -0.21 & 1.00 & & & & \\
\hline $\mathrm{Zn}$ & -0.04 & 0.00 & -0.07 & 0.00 & -0.03 & -0.07 & -0.14 & 0.05 & 1.00 & & & \\
\hline $\mathrm{Na}$ & 0.83 & $-0.86^{b}$ & $-0.28^{a}$ & $-0.61^{b}$ & $-0.28^{a}$ & $0.47^{b}$ & $-0.38^{b}$ & 0.22 & 0.01 & 1.00 & & \\
\hline $\mathrm{K}$ & 0.74 & $-0.72^{b}$ & $-0.26^{a}$ & $-0.57^{b}$ & -0.22 & $0.47^{b}$ & $-0.25^{a}$ & 0.16 & -0.05 & $0.86^{b}$ & 1.00 & \\
\hline $\mathrm{NA} / \mathrm{K}$ & 0.65 & $-0.73^{b}$ & -0.20 & $-0.47^{b}$ & $-0.28^{a}$ & $0.34^{b}$ & $-0.37^{b}$ & 0.22 & 0.08 & $0.83^{b}$ & $0.44^{b}$ & 1.00 \\
\hline
\end{tabular}

${ }^{a}$ Correlation is significant at the 0.05 level (2-tailed). ${ }^{\mathrm{b}}$ Correlation is significant at the 0.01 level (2- tailed).

subjects (Table 5).

The mean ranges of the micronutrient levels were as follows: vitamin C $14.96 \pm 1.92 \mathrm{mg}$ (male hypertensive patients) and $40.87 \pm 4.18 \mathrm{mg}$ (controlled female subjects), calcium $0.11 \pm 0.02 \mathrm{mg}$ (female hypertensive subjects) and $0.56 \pm 0.14 \mathrm{mg}$ (controlled male subjects), zinc $0.03 \pm 0.01 \mathrm{mg}$ (male hypertensive patients) and $0.05 \pm 0.01 \mathrm{mg}$ (female subjects), magnesium $3.33 \pm 0.54$ $\mathrm{mg}$ (controlled female subjects) and $6.91 \pm 0.48 \mathrm{mg}$ between systolic blood pressure and age $(\mathrm{r}=0.52)$, $\mathrm{BMI}(\mathrm{r}=0.42)$ and magnesium $(\mathrm{r}=0.31)$; and inverse correlations with vitamin $\mathrm{C}(\mathrm{r}=-0.4)$, sodium $(\mathrm{r}=-0.6)$ and potassium $(\mathrm{r}=-0.57)$ of the subjects. Likewise, there were positive correlations between the diastolic blood pressure (DBP) and age $(\mathrm{r}=0.25)$, BMI $(\mathrm{r}=$ $0.33)$, magnesium level $(\mathrm{r}=0.12)$ and calcium $(\mathrm{r}=$ $0.10)$; and also, inverse correlation with vitamin $\mathrm{C}(\mathrm{r}=$ $-0.27)$, zinc $(\mathrm{r}=-0.03)$, sodium $(\mathrm{r}=-0.28)$, potassium $(\mathrm{r}=-0.22)$ and $\mathrm{Na} / \mathrm{K}$ ratio $(\mathrm{r}=-0.28)$ (Table 7$)$. 


\section{Discussion}

In this present study, it was observed that large proportion of hypertensive patients was women; and also, the proportion of subjects that had high blood pressure belonged to $\geq 60$ years. Epidemiological studies have reported that there were no clear patterns of association between high blood pressure and gender, some of the studies reported high prevalence among men than women (Cappuccio et al., 2004); while others reported that hypertension was more common in women than men (Amoah, 2003). It was evident in this study that a large proportion of hypertensive subjects were obese. This observation could be attributed to the fact that most of the patients were above 60 years of age and many of them were living sedentary lifestyles, hence gaining weight. A number of studies have reported that there is an association between sedentary lifestyle, gaining weight and development of high blood presure (Aneja et al., 2004). These authors have also shown that weight reduction is one of the most effective ways to manage hypertension, particularly for obese hypertensive patients.

The nutritional knowledge of the hypertensive patients was significantly lower compared to the control subjects. This observation could be attributed to the educational attainment of large proportion of the control subjects against the hypertensive patients. In the present study it was observed that about four-fifth of the hypertensive patients had secondary education and below compared to three-fifth of the control subjects that belonged to this category. Evidences have shown that hypertension could be successfully prevented or managed through good knowledge of nutrition and health, that is, through lifestyle modifications, such as smoking cessation, weight reduction, moderation of alcohol consumption, reduction of salt intake and increase physical activity (Chalmervs et al., 2000; Aneja et al., 2004).

The mean dietary intake of the subjects showed that hypertensive patients consumed less energy giving food and minerals (calcium, zinc, magnesium, sodium, potassium) than the control subjects. However, the vitamin $\mathrm{C}$ intake of the hypertensive patients was absolutely higher than the controlled subjects. This observation could be attributed to the health counselling that was usually rendered to hypertensive patients by health professionals during clinic days. It is evident from epidemiological studies that reduction in energy intake prevent obesity, hence hypertension (Aneja et al., 2004); and also, intake of micronutrient, such as vitamin $\mathrm{C}$ and potassium, helps to prevent high blood pressure (Ettarh et al., 2002). The micronutrient status of the respondents showed that the vitamin $\mathrm{C}$, sodium, potassium and $\mathrm{Na} / \mathrm{K}$ ratios status of the hypertensive patients were significantly lower compared to the control subjects. This finding could be attributed to low intake of foods that contain these micronutrients by the hypertensive patients. Studies have shown that the micronutrient status of individuals, particularly vitamin C, potassium and magnesium, helps to manage hypertension (Kotchen et al., 1991; Reusser et al., 1994).It was established in this study that there were weak correlations between systolic blood pressure and age and urinary magnesium level; and inverse correlations with vitamin $\mathrm{C}$, sodium and potassium of the subjects. It is well known that the risk of hypertension increases with age; and that it is more common in people over the age of 60 than in younger persons and that the plasma levels of vitamin $\mathrm{C}$, potassium and sodium have significant roles in controlling high blood pressure (Reusser et al., 1994).

In conclusion, the findings of this study have shown that there are positive correlations between the SBP and age, BMI and magnesium level, and inverse correlation with vitamin $\mathrm{C}$, sodium and potassium level of the subjects. The study further established that there are positive correlations between the DBP and age, BMI, magnesium and calcium; and inverse correlation with vitamin $\mathrm{C}$, zinc, sodium, potassium and $\mathrm{Na} / \mathrm{K}$ ratio. In view of the importance of micronutrients in the prevention and control of hypertension more study should therefore be conducted on other micronutrients which are not included in the present study.

Received 3 August 2007

Revised 4 February 2008

Accepted 5 February 2008

\section{References}

Amoah, A.G.B. (2003) Hypertension in Ghana: a cross-sectional community prevalence study in Greater Accra. Ethnicity and Disease 13, 310-315.

Aneja, A., El-Atat, F., McFarlane, S.I. \& Sowers, J.R (2004)

Hypertension and obesity. Recent Progress in Hormone Research 59, 169-205.

AOAC (1990) Official Methods of Analysis. 16th edition. The Scientific Arlington V.AAssociation of Dedicated to Analytical Excellence. AOAC International Official Analytical Chemist.

Awoyemi, A.O., Osagbemi, G.K., Ogunleye, V.A. (2001) Medical examination findings among army recruits in Ilorin. West African Journal of Medicine 20, 256-258. 
Birkett, N.J. (1998) Comments on a meta-analysis on the relationship between dietary calcium intake and blood pressure. American Journal of Epidemiology148, 223-228.

Blackburn, H. \& Prineas, R. (1983) Diet and hypertension: anthropology, epidemiology, and public health implications. Progress in Biochemical Pharmacology 19, 31-79

Cappuccio, F.P., Micah, F.B., Emmett, L., Kerry, S.M., Antwi, S., Martin-Peprah, R., Phillips, R.O., Plange-Rhule, J. \& Eastwood, J.B. (2004) Prevalence, detection, management, and control of hypertension in Ashanti, West Africa. Hypertension 43, 1017.

Cardiovascular News (2005). Global hypertension rise threatens CVD epidemic. Lancet 365, 217-223.

Chalmervs, J., Chisid, P., Cohn, J.N., Martin, I.M., Rahn, K. \& Sleight, P. (2000) Practice guidelines for primary care physicians 1999 . WHO/ ISH Hypertension Guidelines. Nigerian Journal of General Practice 4, 21-25.

Cooper, R., Rotimi, C., Ataman, S., McGee, D., Osotmehin, B., Kadiri, S., Muna, W., Kingue, S., Fraser, H., Forrester, T., Bennett, F. \& Wilks, R. (1997) The prevalence of hypertension in seven populations of West African origin. American Journal of Public Health 87, 160-168.

Cooper, R.S. \& Rotimi, C. (1993) Establishing the epidemiologic basis for prevention of cardiovascular diseases in Africa. Ethnicity and Disease 3, S13-S22.

Ekere, A.U., Yellowe, B.E. \& Umune, S. (2005) Mortality patterns in the accident and emergency department of an urban hospital in Nigeria. Nigerian Journal of Clinical Practice 8, 14-18.

Ettarh, R.R., Odigie, I.P. \& Adigun, S.A. (2002) Vitamin $\mathrm{C}$ lowers blood pressure and alters vascular responsiveness in salt induced hypertension. Canadian Journal of Physiology and Pharmacology 80, 199-1202.

Friedman, G.D., Klatsky, A.L. \& Siegelaub, A.B. (1983) Alcohol intake and hypertension. Annals of Internal Medicine 98, 846-849.

Gibbson, R.S. (1990) Principles of Nutritional Assessment. Oxford University Press. 1990.

Hagberg, J.M., Park, J.J. \& Brown, M.D. (2000) The role of exercise training in the treatment of hypertension: an update. Sports Medicine 30, 193-206.
Heyka, R. (1999) Lifestyle management and prevention of hypertension. In: J. Rippe (ed). Lifestyle Medicine. 1st ed. Malden, Mass: Blackwell Science; pp.1999: 109-119.

JNC7 (2004) The Seventh Report of the Joint National Committee on Prevention, Detection, Evaluation, and Treatment of High Blood Pressure. Journal of American Medical Association 289, 2560-2572.

Kotchen, T.A., Kotchen, J.M. \& Boegehold, M.A. (1991) Nutrition and hypertension prevention. Hypertension 18, (Suppl 3), 115-120.

Leela, R., Yasodhara, P., Ramaraju, M.B.B.S. \&, Ramaraju, L.A. (1991) Calcium and magnesium in pregnancy. Nutrition Research 11, 1231-1236.

Marcous, S., Brisson, J. \& Fabia, J. (1991) Calcium intake from dairy products and supplements and the risk of preeclampsia and gestational hypertension. American Journal of Epidemiology 133, 1226-1272.

May, J.M. (2000) How does ascorbic acid prevent endothelial dysfunction? Free Radical Biology and Medicine 28, 1421-1429.

Murray, C.J. \& Lopez, A.D. (1997) Mortality by cause for eight regions of the world. Global Burden of Disease. Lancet 349, 1269-1276.

Okojie, O.H., Isah, E.C. \& Okoro, E. (2000) Assessment of health of senior executives in a developing country. Public Health 114, 273-275.

Prada, J.A., Ross, R. \& Clark, K.E. (1992) Hypocalcemia and pregnancy-induced hypertension produced by maternal fasting. Hypertension 20, 620-626.

Reusser, M., Olly, E. \& McCarron, David A. (1994) Micronutrient effects on blood pressure regulation. Nutrition Reviews 52, 367-375.

Shaper, A.G., Wright, D.H. \& Kyobe, J. (1969) Blood pressure and body built in three nomadic tribes of northern Kenya. East African Medical Journal 46, 273-281.

Temple, N.J. (1999) Survey of nutrition knowledge of Canadian physicians. Journal of the American College of Nutrition 18, 26-29.

WHO (1995) Physical Status: The Use and Interpretation of Anthropometry. Report of a WHO Expert Committee. WHO Technical Report Series. 854, 1-452.

WHO (2002) Reducing Risks, Promoting Healthy Life. Geneva, Switzerland: World Health Organization; 2002. Geneva, Switzerland.

Wolf-Maier, K., Cooper, R.S., Banegas, J.R., Giampaoli, S., Hense, H., Joffres, M., Kastarinen, M., Poulter, N., Primatesta, P., Rodriguez-Ar- 
talejo, F., Stegmayr, B., Thamm, M., Tuomilehto, J., Vanuzzo, D. \& Vescio, F. (2003) Hypertension prevalence and blood pressure levels in 6 European countries, Canada, and the United States (2003). Journal of American
Medical Association 289, 2363-2369.

Wynn, A. \& Wynn, M. (1988) Magnesium and other nutrient deficiencies as possible causes of hypertension and low birthweight. Nutrition and Health 6, 69-88. 